\section{National Birth Defects Prevention Month and Folic Acid Awareness Week — January 2017}

The Zika virus disease outbreak has led to renewed focus on how some birth defects are caused by infection during pregnancy. "Prevent Infections for Baby's Protection" is the theme of January 2017's National Birth Defects Prevention Month. Birth defects are common, costly, and critical, and they affect one in 33 U.S. babies annually (1). Not all birth defects can be prevented, but women can increase their chances of having a healthy baby by reducing their risk for getting an infection during pregnancy.

Women can take the following steps to prevent infections: talk to their health care provider about how they can reduce their risk for infections with viruses such as Zika and congenital syphilis, if they are pregnant or currently planning a pregnancy (2); properly prepare food to avoid illnesses, such as listeriosis (3); protect themselves from insects and animals known to carry diseases, such as Zika and toxoplasmosis (4); and maintain good hygiene to prevent infections, such as cytomegalovirus (5). CDC encourages everyone to join this nationwide effort to raise awareness of birth defects, their causes, and their impact. Additional information is available at https://www.cdc.gov/ ncbddd/birthdefects/prevention-month.html.
January 8-14, 2017, is National Folic Acid Awareness Week. CDC urges all women who can become pregnant to get $400 \mu \mathrm{g}$ of folic acid every day to help reduce the risk for serious birth defects of the brain and spine (spina bifida and other neural tube defects) (G). Women can get folic acid from fortified foods or supplements, or both. Additional information about folic acid is available at http://www.cdc.gov/folicacid.

\section{References}

1. CDC. Update on overall prevalence of major birth defects-Atlanta, Georgia, 1978-2005. MMWR Morb Mortal Wkly Rep 2008;57:1-5.

2. CDC. For women in areas with Zika: plan your pregnancy. Atlanta, GA: US Department of Health and Human Services, CDC; 2016. http:// www.cdc.gov/zika/pdfs/zika-plan-your-pregnancy.pdf

3. US Department of Agriculture. Food safety for pregnant women. Silver Spring, MD: US Department of Agriculture, Food and Drug Administration; 2011. http://www.fda.gov/downloads/Food/ FoodborneIllnessContaminants/UCM312787.pdf

4. CDC. Pregnant? Protect yourself from mosquito bites. Atlanta, GA: US Department of Health and Human Services, CDC; 2016. http://www. cdc.gov/zika/pdfs/zika-pregnancy.pdf

5. Cannon MJ, Davis KF. Washing our hands of the congenital cytomegalovirus disease epidemic. BMC Public Health 2005;5:70. http:// dx.doi.org/10.1186/1471-2458-5-70

6. Honein MA, Paulozzi LJ, Mathews TJ, Erickson JD, Wong LY. Impact of folic acid fortification of the US food supply on the occurrence of neural tube defects. JAMA 2001;285:2981-6. http://dx.doi.org/10.1001/ jama.285.23.2981 